\title{
El papel de la prensa obrera del siglo XX: Cronología en Costa Rica y el trabajo de la UNED por resguardar el patrimonio documental
}

\author{
Miguel Mondol Velásquez* \\ José Pablo Meza Pérez**
}

Recibido: Abril 2012 • Aceptado: Mayo 2012

\begin{abstract}
RESUMEN
Abarca la concepción marxista-leninista del papel de los medios escritos partidarios y su importancia para reconocer su relevancia como fuente de información para la investigación. Presenta una cronología de las diferentes series documentales públicas por el Partido Comunista en el siglo XX y detalla el avance del proceso de digitalización e indización del Semanario Libertad, por parte de la Vicerrectoría de Investigación y de las cátedras de Tecnologías de la Información y Manuel Mora de la Escuela de Ciencias Sociales y Humanidades, de la Universidad Estatal a Distancia.

Palabras clave: publicaciones seriadas, Partido Comunista, siglo XX, medios de comunicación.
\end{abstract}

\begin{abstract}
Manuel Mora Valverde was an important 20th Century political leader in Costa Rica. This article includes the Marxist-Leninist conception of the role of party printed media and their importance as research sources, and presents a chronology of public document series produced by the Costa Rican Communist Party in the 20th Century. At UNED, the Costa Rican Distance University has a documentation project on Mora's work. The Information Technology Chair and the Manuel Mora Chair at the School of Social Sciences and Humanities are in the process of cataloguing and digitalizing the weekly party journal, Semanario Libertad, in collaboration with the Research Vice-presidency: here I summarize advances in this project. Key words: serial publications, Communist Party, 20th. Century, mass media.
\end{abstract}

\footnotetext{
* Encargado de la Cátedra Manuel Mora Valverde, ECSH-UNED. E-mail: mmondol@uned.ac.cr

** Encargado de la Cátedra de Tecnologías de la Información, ECSH-UNED.

E-mail: jmezap@uned.ac.cr
} 


\section{Introducción}

\section{Concepto de prensa} comunista y su rol en las luchas revolucionarias durante el siglo $X X$

En Europa y para principios del siglo XX, el grupo llamado de los marxistas hegelianos estaba claro en la importancia de tres aspectos para toda estrategia revolucionaria, y Costa Rica no fue la excepción. Los temas eran:

1. La conciencia de clase es un elemento fundamental para transformar a "una clase en sí" a una "clase para sí", es decir, capaz de actuar en el nivel más importante de lucha de clases: la lucha política, en procura de la transformación revolucionaria de su sociedad.

2. La conciencia de clase obrera (o trabajadora en general) no surge espontáneamente, sólo como un resultado mecánico de las condiciones objetivas de explotación que sufre esa clase social. Incluso una explotación máxima y objetiva no necesariamente implicará un mayor desarrollo de su conciencia como clase.

3. La conciencia de clase surge de las condiciones objetivas, pero también del trabajo político que se realice con la clase obrera (o trabajadora en general).

Le correspondió a Lenin concretar estos aspectos en una estrategia revolucionaria para una realidad específica (la rusa de principios de siglo XX). Dentro de esta estrategia, Lenin le dio particular importancia a la palabra escrita y cotidiana, es decir, al periódico revolucionario, en el proceso de transformación de una clase en sí hacia una clase para sí, tal como las había conceptualizado Marx.

"Al obrero se le puede dotar de conciencia politica de clase desde fue$r a$, es decir, desde fuera de la lucha económica, desde fuera del campo de lucha entre obreros y patronos (...) Hay que ir a los obreros para aportar a los obreros conocimientos políticos..." (Lenin, 1970: 179)

Una forma de ir a los obreros era elaborar y distribuir un periódico para ellos, el cual reivindicara sus intereses. Un periódico que: a) los formara políticamente, b) contribuyese a la organización de la clase obrera y c) incentivara luchas concretas para reivindicar derechos de los trabajadores. Textualmente, decía Lenin:

Con respecto a la organización del partido político: "El vínculo efectivo empezaría ya a crearse por la función de difusión del periódico 
(...) Inmediatamente adquiriría la labor de organización una envergadura mucho mayor..." (1970: 259).

En relación con el propósito de incentivar la lucha reivindicativa: "Este periódico sería una partícula de un enorme fuelle de forja que atizase cada chispa de la lucha de clases y de la indignación del pueblo, convirtiéndola en un gran incendio" (1970: 260).

Orientados por estos principios leninistas, muchos dirigentes obreros costarricenses de finales del siglo XIX y de la primera mitad del siglo $\mathrm{XX}$ consideraron al periódico una herramienta fundamental para ganar adeptos para la "causa revolucionaria". Pero, asimismo, ellos pretendían partidarios capacitados políticamente, por lo cual la palabra escrita adquirió una doble importancia. Además de simpatizantes y seguidores, los querían diestros en la argumentación política.

A partir de 1883 iniciaron, en Costa Rica, publicaciones específicamente dirigidas al estrato artesanal y obrero. Ejemplos son $\mathrm{El}$ Artesano, de 1889, y El obrero, del año siguiente. Se trata de periódicos rudimentarios, muy orientados hacia la organización de los artesanos en sociedades de ayuda mutua.

Un nivel mayor de elaboración y de formación política se observará en los periódicos de la primera década del siglo XX, como la Hoja Obrera (1909) y la Aurora Social (1911). Con el inicio de la Primera Guerra Mundial, varias de estas publicaciones desaparecieron. Pero la semilla estaba sembrada. Al respecto, ha dicho un estudioso del tema:

“...todas estas publicaciones eran claros síntomas del renacer del movimiento artesano-obrero de principios del siglo XX. El movimiento, en estos años, conformó su estilo y vitalidad a partir de la prensa. [...] Jugó un papel importante de propaganda y difusión del pensamiento socialista, orientó el movimiento social y ayudó a configurar desde sus páginas la conciencia del pueblo trabajador." (Oliva, 2009: X)

El sábado 15 de marzo de 1930 apareció el Semanario Revolución, bajo la dirección de dos jóvenes veinteañeros: Ricardo Cote Conde y Manuel Mora Valverde. Consideramos que su emergencia marcó diferencias en relación con la prensa obrera anterior. Para empezar, se ajusta a las orientaciones leninistas que vimos en párrafos anteriores. Así, desde su primera página se mencionan sus propósitos, los cuales concuerdan con esas orientaciones:

"Obreros de Costa Rica: ;La revolución os saluda 
La Revolución quiere ser vuestra amiga; quiere ser el vehículo de vuestras aspiraciones, quiere ser la defensora de vuestros derechos; quiere ser vuestra voz!... La 'revolución aspira a abriros los ojos a los que de vosotros los tenéis cerrados...", (La Revolución, 2009: 1)

En segundo término, Revolución emerge como un periódico obrero donde escriben obreros junto a intelectuales importantes de la época. $\mathrm{Al}$ respecto, ha dicho Mario Oliva (2009: XI):

"En sus páginas escribían personajes que se identificaban con la causa de los trabajadores o, en menor proporción, obreros propiamente dichos. Creemos que alli radica el mérito principal de este periódico, que se definía como portavoz del mundo obrero y del pueblo en general."

Por las razones apuntadas, consideramos que encabezada por el Semanario Revolución y a partir de la década de los años 30 del siglo pasado, emergió y se consolidó en el país -hasta la década de los ochenta- una prensa obrera, fiel a los principios leninistas para la educación y organización de la clase trabajadora, en procura de su transformación de una clase en sí hacia una clase para sí.

\section{Evolución de los medios de comunicación impresos del Partido Comunista de Costa Rica}

Los medios de comunicación impresos del Partido Comunista de Costa Rica fueron publicados casi en forma continua, desde el inicio de la década de los años 30 hasta finales de la década de los años 80 del siglo XX. Sin embargo, se presentaron en diferentes formatos, como hojas sueltas, revistas y semanarios de circulación nacional.

Algunos de los cambios de nombre y formatos se debieron a las circunstancias políticas de la época, como el Periódico Trabajo, en el año 1948; el cierre del Semanario Adelante, en octubre de 1962; y la división partidaria de finales del año 1983 que generó dos series documentales del semanario, Libertad y Libertad Revolucionaria, utilizando ambas como propia la misma numeración de la serie original.

Las series documentales de los medios de comunicación impresos del Partido Comunista fueron las siguientes:

\section{Periódico Revolución}

Aunque este se presentaba como un semanario demócrata, es 
la serie documental más antigua y predecesora de las publicaciones del Partido Comunista de Costa Rica. La Cátedra Manuel Mora, de la Escuela de Ciencias Sociales y Humanidades de la UNED, realizó, en el año 2009, una reproducción de ese semanario que permitió rescatar parte del patrimonio documental costarricense y entregó copias a la Biblioteca Nacional, pues no contaba con el registro de la publicación.

Esta serie documental fue editada por Ricardo Coto Conde y Manuel Mora Valverde, ambos fundadores del Partido Comunista de Costa Rica. Se publicó del 15 de marzo al 17 de mayo de 1931 y estuvo constituida por 10 números. Su formato era de tabloide, de cuatro hojas y su costo era de 10 céntimos.

\section{Periódico Trabajo}

La fecha de su primera edición se registró el día 14 de julio de 1931. Sin embargo, como hecho curioso, la fundación del Partido Comunista fue el 16 de junio; pero para esa fecha la primera edición todavía no estaba totalmente impresa, lo cual permitió incluir la constitución del Comité Ejecutivo del Partido Comunista, en la página cuatro de ese primer número.

El periódico fue dirigido por Ricardo Coto Conde, se publicó en formato tabloide, de periodicidad mensual, entre los años 1931 y 1932; después de ese año, se convirtió en un semanario hasta días antes de las elecciones de febrero de 1948, con un costo de 10 céntimos. Después del conflicto armado de marzo a mayo de ese año, tras la expulsión a México de María Isabel Carvajal (Carmen Lyra) y Manuel Mora, así como el arresto de la dirigencia partidaria, el periódico se dejó de publicar por unos meses.

El lapso entre los años 1948 y 1951 fue un periodo de publicaciones discontinuas del periódico Trabajo, debido a la ilegalidad de los comunistas y la reorganización de la estructura partidaria.

En los días posteriores al 8 de mayo de 1948 y pese a su ilegalización, el Partido Comunista de Costa Rica pudo mantener una estructura organizativa. Como lo señala Contreras (2006), una pieza clave en esos días lo fue la escritora Luisa González, quien debió hacerse cargo de la desmovilización de una parte de los excombatientes y de organizar la red de contactos para ayudar a sus compañeros de partido presos y sus familiares. Asimismo, de distribuir los pocos recursos de la organización.

Después de ese periodo y con la liberación de parte de los detenidos, gracias a los oficios de muchas personas y los esfuerzos de Monseñor Sanabria por garantizar su integridad física, se realizaron 
publicaciones del periódico Trabajo -en forma rudimentaria- en la casa de militantes, como lo reseña Vargas (2007) en su intervención en conmemoración de los 75 años del asesinato del Codo del Diablo.

A la fecha, no existen ejemplares de ese período, pues su formato y circulación fue limitada. Testimonialmente, se sabe que fue publicado de nuevo a finales de 1948. Su impresión se realizó en las cercanías del Colegio de Costa Rica, en la casa de la familia Pérez Castillo. Intelectuales como el profesor universitario y escritor Víctor Arroyo y otros elaboraban los esténciles. En las noches, con una radio encendida para evitar llamar la atención de los vecinos, la familia lo mimeografiaba y, a la mañana siguiente, se distribuía (Pérez, 2012).

\section{Periódico Adelante}

En el año 1952, se comenzó a publicar el Periódico Adelante, en formato tipo tabloide, de periodicidad semanal; sus primeros directores fueron Fernando Gutiérrez, Humberto Vargas Carbonell, hasta el año 1959, y el último fue el educador herediano Mario Solís (Solís, 1962).

Sin embargo, a raíz del triunfo de la Revolución Cubana y el creciente endurecimiento de la política internacional hacia la isla, más la campaña anticomunista después de la crisis de los misiles en octubre de 1962, el semanario comenzó a ser hostigado e intimidado.

Según reseña Gamboa (1980), el hostigamiento que obligó al cierre del Periódico Adelante fue realizado por medio de una Junta de Censura, la cual se extralimitó en sus funciones, pues solo debía controlar la pornografía, llegando las autoridades hasta a decomisar la circulación del periódico, a finales de octubre de 1962.

Después de esas acciones, se decidió buscar otro medio de difusión para resguardar el derecho a la libertad de expresión. También Gamboa (1980) menciona que después del cierre de Adelante, se publicó un periódico clandestino por dos semanas, que se llamó el Yunque, del cual no se conocen ejemplares.

\section{Semanario Libertad}

Este periódico es la serie documental impresa más extensa que se le conoce al Partido Comunista de Costa Rica. Su nombre se debió a la búsqueda de una estrategia por defender el derecho de expresión y nuestras libertades democráticas, después del cierre del Semanario Adelante. El educador Ovidio Salazar fue su primer director e inscribió legalmente el Semanario Libertad, que se presentó como un 
periódico independiente entre los años 1962 y 1975.

La circulación de Libertad, en especial los primeros números, representó un reto, logrando un asidero legal al interponer un recurso de amparo ante el Juez Penal de Turrialba, según consta en el artículo intitulado "Tribunales dan amparo a la libertad de prensa" (1962: 1).

En el número 3 del periódico del 24 de noviembre de 1962, se publicó la siguiente nota:

\section{"Advertencia \\ El artículo 264 del Código Penal dice <abre comillas> Sufrirá la pena del artículo anterior (300 a mil colones de multa) el que impida la libre circulación de un libro, un periódico, o cualquier otro impreso, a menos que éste contenga produc- ciones literarias o gráficas contra- rias a la honestidad y que quien obre sea la autoridad competente < cierra comillas> con base en este artículo y en el 29 de la Constitu- ción acusaremos a todo aquel que se incaute de uno o varios ejemplares de este periódico." (p. 1)}

Los comunistas costarricenses consideran un triunfo al derecho a la libertad de expresión la estrategia empleada para legitimar y consolidar el Semanario Libertad, aunque este también consigna, a través de su historia, varios incidentes con corresponsales, periodistas, fotógrafos, redactores, pregoneros y decomiso de ejemplares.
Sus directores fueron Ovidio Salazar (de 1962 a 1971), Eduardo Mora Valverde (de 1972 a 1981) y Francisco Gamboa Guzmán (de 1982 a 1984). En la serie original, fue impreso en la Imprenta Elena y en Litografía Cosmos.

En el año 1975, el Semanario Libertad se publicó como el órgano oficial del Partido Vanguardia Popular, hasta el año 1983 en su serie original. Una división interna de este Partido, a finales del año 1983 (Dobles y Leandro, 2005), enfrentó a sus dirigentes históricos.

El fraccionamiento del Partido Comunista de Costa Rica fomentó la desaparición de unas organizaciones y el surgimiento de otras. Una de ellas fue el Partido del Pueblo Costarricense, que mantuvo el nombre del Semanario Libertad. El sector partidario que conservó el nombre de Partido Vanguardia Popular publicó una nueva serie documental, llamada Semanario Libertad Revolucionaria.

Ambas series utilizaron la misma periodicidad de la serie original, del año 1962, después del número 1059 de enero de 1984. Tal hecho se presta a confusiones al citarlo como fuente de información; y ambas series se dejaron de publicar a inicios de la década de los noventa, después de la disolución del Bloque del Este de los Países Socialistas.

La serie documental de $\mathrm{Li}$ bertad Revolucionaria tuvo como 
director, de 1984 a 1989, a Francisco Gamboa Guzmán. Por su parte, los directores de Libertad -de la serie documental del Partido del Pueblo Costarricense- fueron, de 1984 a 1988, Eduardo Mora Valverde y, de 1988 a 1989, Rodolfo Ulloa.

Otras series documentales relacionadas con el Partido Comunista de Costa Rica son las siguientes:

\section{Revista Vanguardia}

Esta serie fue una revista literaria publicada entre los años 1941 y 1942. En el 2010, en colaboración con la línea editorial de la UNED, la filóloga Laura Casasa publicó una compilación de cuentos e ilustraciones en el libro El disecador de abuelitas, cuentos costarricenses de la década de 1940.

La periodicidad e impacto en el campo literario es desconocido. Sin embargo, el esfuerzo por rescatar este conjunto de cuentos, producto de un concurso público y calificado por un jurado representado por reconocidos personajes de la talla del poeta Julián Marchena, el abogado Emilio Valverde, el escritor Adolfo Herrera García y el literato Abelardo Bonilla, hacen suponer que fue una propuesta literaria seria.

\section{Periódico Juventud}

Este periódico fue el órgano oficial de la Juventud Vanguardista
Costarricense; su publicación fue mensual, en el periodo comprendido entre 1979 a 1982. Su primer director fue el profesor universitario César Solano. Sobre esta publicación, son pocos los datos que se conocen y los números publicados.

\section{Revista Trabajo}

Se publicó como una revista oficial del Comité Central del Partido Vanguardia Popular y se editó en forma esporádica; entre los años 1980 y 1982, se publicaron 13 números. Trataba temas de análisis de la realidad nacional e internacional.

Periódico Adelante: nueva época

En la década de los noventa del siglo XX, el Partido Vanguardia Popular editó nuevamente el Periódico Adelante. $\mathrm{Su}$ periodicidad fue discontinua, entre 1990 y 1991; después, se publicó en forma continua entre los años 1992 y 1993.

\section{Un esfuerzo importante por resguardar el patrimonio documental: hacia la recuperación, digitalización e indización del Semanario Libertad}

Durante el año 2009 y con el apoyo de la Editorial de la Universidad Estatal a Distancia, la Cátedra 
Manuel Mora (UNED) y el Centro de Estudios Manuel Mora reeditaron los diez primeros números del Semanario Revolución, primer medio de expresión escrita de carácter comunista en el país. Esta experiencia nos acercó a dimensionar la importancia de la prensa comunista en Costa Rica durante el siglo XX.

Consecuentemente, en el año 2011, con el apoyo de la Vicerrectoría de Investigación y la Dirección de la Escuela de Ciencias Sociales y Humanidades, la Cátedra de Tecnologías de la Información y la Cátedra Manuel Mora iniciamos un proceso de recuperación, digitalización e indización del Semanario Libertad, orientado por las siguientes consideraciones:

1. Los semanarios Libertad y Libertad Revolucionaria son un aporte significativo como fuente de información del acontecer nacional, la vida pública, la acción parlamentaria de los diputados de izquierda, temas conflictivos y la fiscalización de la función pública. A través de los semanarios también se promovieron importantes leyes para el país.

2. Muchos intelectuales distinguidos escribieron en estos semanarios, aportando reflexiones importantes sobre la vida nacional. Un ejemplo: en el año
1975, el escritor Adolfo Herrera García fue merecedor del Premio Nacional Pío Víquez por la sección, en el Semanario Libertad, denominada "Columna Subversiva". También destaca la obra de Luisa González y los caricaturistas nacionales Fernando Zeledón y Hugo Díaz, en la sección "La Semana en Serio", y podría ser valorada como una forma pionera de educación popular en nuestro país.

3. Esta información se puede llegar a perder por el endeble soporte documental de papel periódico, de alta acidez y poca calidad de sus tintas e impresión, en que fueron publicadas las dos series documentales que se propone investigar $\mathrm{y}$ digitalizar. Ello implica un esfuerzo urgente para su conservación. Las pocas colecciones existentes son escasas e incompletas y en el mediano plazo es inminente el riesgo de que se degraden paulatinamente y pierdan detalles de imágenes, diseño y contenido.

4. La investigación social, a partir de la elaboración de un fondo documental de ambos semanarios, permitirá satisfacer la necesidad de visibilizar la participación de los sectores 
sociales en los procesos de transformación, participación, construcción de organizaciones y lucha por mejorar las condiciones de vida de las comunidades y del país. Entendemos que la aplicación de técnicas bibliométricas permite hacer visible el registro de los actores sociales en la vida nacional.

En síntesis, el proyecto se orienta por el siguiente objetivo: describir el quehacer de las organizaciones sociales costarricenses durante el periodo 1962-1983, construyendo y utilizando el fondo documental de los semanarios $L i$ bertad y Libertad Revolucionaria, y su avance a la fecha es el siguiente:

Se han identificado los ejemplares completos que integran el fondo documental de los semanarios Libertad y Libertad Revolucionaria para su digitalización. Se encuentra identificado el $85 \%$ de la colección; resta por localizar y lograr el préstamo del $15 \%$ restante para su tratamiento.

Sin embargo, existen ejemplares en muy mal estado y de conservación precaria que hay que determinar. Este esfuerzo realizado equivale a 4179 imágenes diferentes de los ejemplares del Semanario Libertad. Para completar este objetivo, se han identificado dos colecciones privadas las cuales, esperamos, nos permitirán a futuro completar los ejemplares faltantes y deteriorados.

Se ha desarrollado una interface para disco compacto, orientada a la fácil recuperación de la información y visualización de las imágenes en software de licencia de utilización libre con lo cual se ha logrado realizar una mejora para lograr la distribución del material a futuro.

\section{Conclusiones}

El desarrollo de la prensa obrera ligada al Partido Comunista, en el siglo $\mathrm{XX}$, representa tanto un buen testimonio de la acción y participación sociales de dicho periodo, en contraposición con la prensa de los sectores dominantes, como una contribución para contextualizar los aportes de los diferentes sectores. Además, constituye un referente ideológico para la época.

La cronología de medios de comunicación expuesta en este artículo es un instrumento importante para el investigador, porque identifica claramente las fuentes informativas y sus características. También, establece el reto por recuperar algunas fuentes de datos que se consideran desaparecidas.

El proyecto de digitalización de la serie documental Libertad es una tarea de gran relevancia, porque esta es la fuente de información 
documental más extensa publicada por el Partido Comunista. Además, recoge una segunda etapa del desarrollo de este Partido, cuando logró su legalidad e integración a los diferentes procesos electorales -y hasta la elección de diputados, regidores-; asimismo, el aporte de importantes intelectuales y la participación, en forma activa, en el panorama político costarricense.

\section{Bibliografía}

Contreras, G. (2006). Luisa González: una vida y trayectoria consecuente. Revista Comunicaciones. Instituto Tecnológico de Costa Rica. 15 (2): 113-119.

Dobles Oropeza, I. y Leandro Zúñiga, V. (2005). Militantes: La vivencia de lo político en la segunda ola del marxismo en Costa Rica. San José: ECR.

Gamboa, F. (1980). Así mataron Adelante, así nació Libertad. Libertad (866): 7.
La Revolución. (2009). Cátedra Manuel Mora, EUNED.

Lenin, V. I. (1970). Obras escogidas. (Tres tomos). Moscú: Progreso.

Oliva Medina, M. (2009). La revolución, antesala del periodismo comunista costarricense. Periódico La Revolución, X. Cátedra Manuel Mora, EUNED.

Pérez Castillo, L. (2012). Los medios de comunicación del Partido Comunista costarricense. [Entrevista personal]. San José, 24 de marzo, 2009.

Solís, M. (1962). Carta a Ovidio Salazar, director del Semanario Libertad. Libertad 1(2):1.

Tribunales dan amparo a libertad de prensa. (1962). Libertad 1(3): 1

Vargas Carbonell, H. (2007). El asesinato del Codo del Diablo. A los 75 años de la fundación del Partido Comunista de Costa Rica. Recuperado de: https://groups.google.com/group/ baproees/browse_thread/thread/ b14048dd60409f23?hl=es 
